canons of beauty to give insight into the nature of the world. Lying between pure mathematics and the experimental sciences of physics and chemistry, the results of which remain substantially unaltered, applied mathematics has the surprising difference that it is liable to rapid changes, and its progress consists of the creative process of finding a new set of concepts to transcend the old. The value of such concepts does not depend on their permanence, and some of the best, for example, Bohr's theory of the atom, did not survive unchanged for more than a generation. The essentials, said Prof. Coulson, are the joy, passion and creative impulse, the search for beauty, simplicity and integrity in structure and form, set in an environment partly dependent on, and yet in its deepest sense independent of, experiment and pure mathematics.

\section{Sea Foam}

Sometimes, after heavy and prolonged onshore storms, great masses of foam are drifted in from the sea on to local rocks and beaches. A curious feature of these lather-like masses is the way in which they persist for relatively long periods even when blown about by the wind. Ordinary lathers soon revert to their former unlathered state; but sea foams may persist for a day or more when the weather continues moist and stormy and no sun shines. It is possible that the foam is 'held' by the presence of some protein material, and Miss E. M. Moore suggests that this protein material might be found in the alginate products of sea-weeds. This, however, does not explain how the surface tension of sea-water could be so lowered that the whipping action of storm waves could create a frothy mass (Aust. Mus. Mag., 10, 11 ; 1952). A likely explanation of the phenomenon is that, during storms, large numbers of planktonic organisms are destroyed and broken up because of the battering they receive in choppy seas. The surface tensionlowering chemicals which are thus released into the sea-water would allow the waves to whip up a froth and, if there is also present enough protein matter released from the alginate, a foam with lasting qualities might result.

\section{Surface Photometry of Southern Elliptical Nebulæ}

A PAPER by Dr. David S. Evans on "Surface Photometry of Southern Elliptical Nebulæ", which has been published as No. 19 in the series of "Communications from the Radcliffe Observatory, Pretoria" (reprinted from Mon. Not. Roy. Astro. Soc., 111, 6; 1952), discusses the surface brightness of a group of seven elliptical nebulæ in the region R.A. $3 \mathrm{~h}$. to $4 \mathrm{~h} .30 \mathrm{~m}$. of these nebulæ, four are in pairs and each pair can be photographed on one plate. There is a description of the various details pertaining to the photography, etc., connected with the work, followed by a discussion of the results, which are shown in seven diagrams, these isophotes being drawn with an interval of 0.5 magnitude. In these the dotted lines represent Hubble's distributions in accordance with his law $m=m_{e}+5 \log (r / a+1)$, where $r$ is the distance measured along a radius and $a$ is a constant. While the maps do little more than confirm Hubble's results, there are certain differences of detail which can best be seen in the plot of $N G C$ 1291, the latter showing re-drawings of the central isophotes. There is an obvious rotation of the line of the major axes of successive isophotes, and the natural interpretation of this would be a shear due to rotation. It is asserted that this phenomenon is very probably real in the case of $N G C$ 1291, and Evans thinks that this also applies to $N G C 1549$, although the effect is not so well marked. NGC 1553 presents some anomalies and resembles two elliptical nebulæ, one seen behind the other, though there is no suggestion that this is so. While it scarcely seems correctly classified as a spiral, as an elliptical nebula it is atypical. Observational material on the remaining bright southern elliptical nebulæ is being accumulated, and it is hoped that a detailed discussion will follow in due course.

\section{Papain}

DERIVED by tapping the mature but unripe green fruits of the papaw (Carica papaya), the proteolytic enzyme papain has for a number of years received considerable attention from planters although its market is at present confined largely to the United States. The papaw is indigenous to tropical America, but its cultivation has spread to most tropical countries and its commercial production has hitherto been confined principally to Ceylon and British East Africa (Col. Plant and Animal Prod., 3, No. 1; 1952-53). In the United States papain has five main uses. In the brewing industry it is used for 'chill proofing' beer, while other important applications are in medicine and pharmaceutical preparations ; in the food industry, in pre-cooked foods and in the manufacture of meat-tenderizing preparations ; and, in the textile industry, particularly in shrinkage resistance and other treatment of wool, wool and silk mixtures, and perhaps in silk processing. Papain is used to a much more limited extent in the United Kingdom, and the chief applications may not extend far beyond pharmacy and textiles. In other countries there would appear to bo use for papain in the brewing industry.

\section{Canadian Association of Physicists: Annual Con- gress in London, Ontario}

THE ninth annual congress of the Canadian Association of Physicists will be held during May 28-30 in the University of Western Ontario, London. Prof. J. T. Wilson, professor of geophysics in the University of Toronto and formerly war-time director of operational research in the Canadian Army, will be the after-dinner speaker at the Association's dinner on May 28, and the presidential address on the structure of physical theories will be delivered on May 29 by G. C. Laurence, of Atomic Energy, Ltd. A reception by the board of governors of the University of Western Ontario will follow. The remainder of the programme of the congress will consist of contributed papers, a symposium on the physics of metals, and two invited papers by Prof. M. S. Vallarta, of the El Collegio Nacional de Mexico, on cosmic-ray physics, and by Dr. H. L. Anderson, of the University of Chicago, on the nature of the $\pi$-meson.

\section{Eighth Pacific Science Congress: Meeting in the Philippines}

THe Eighth Pacific Science Congress will be held in the Philippines (in Quezon City, Manila, Los Banos and Baguio) during November 16-28, with headquarters in the Liberal Arts Building, University of the Philippines, Quezon City ; concurrently with this, the Fourth Far Eastern Prehistoric Congress will take place. The programme for the Pacific Science Congress will be organized under the following twelve headings: geology and geophysics, meteorology, oceanography, zoology, botany, soil resources, 